\title{
Giant pituitary adenoma: can it grow bigger than this?
}

Kanwaljeet Garg, Guru Dutta Satyarthee, Manmohan Singh, Bhawani Shankar Sharma

Department of Neurosurgery, All India Institute of Medical Sciences, New Delhi, India

Correspondence to Dr Guru Dutta Satyarthee, duttaguru2002@yahoo.com

\section{DESCRIPTION}

A 40-year-old woman presented with bilateral painless progressive visual diminution and left-sided spastic haemiparesis (power 2/5). Visual acuity in her left eye was $1 / 60$ and she could not perceive light in the right eye. A fundus examination revealed primary optic atrophy in both the eyes. MRI revealed a solid-cystic sellar-suprasellar lesion with a vertical diameter of $10 \mathrm{~cm}$ (figures 1-4). Her prolactin was within normal range. Differential diagnoses of giant sellar-suprasellar lesion include pituitary adenoma, craniopharyngioma and meningioma.

Pituitary tumours are the third most common primary intracranial tumours out of which 5-10\% are giant pituitary adenomas (GPA). ${ }^{1}$ Symon et $a l^{2}$ described pituitary tumours with extension of
$>40 \mathrm{~mm}$ from midline of jugum sphenoidale in any direction or within $6 \mathrm{~mm}$ of foramen of Monro or with extension of intracranial tumour in $\geq 2$ directions as GPA.

GPAs pose a formidable challenge to neurosurgeons and this is affirmed by the high mortality rate reported in various series, ranging from $4.2 \%$ to $18 \% .^{1}$ Various surgical approaches described for GPAs include transsphenoidal, transcranial and combined transsphenoidal and transcranial approaches. Until now there is no conclusive evidence regarding the superiority of one over the other. The reported rates of total tumour excision varies from $14.7 \%$ to $64 \% .^{3}$ An important complication of incomplete tumour excision is the disastrous postoperative residual tumour swelling called the 'postoperative pituitary apoplexy'.

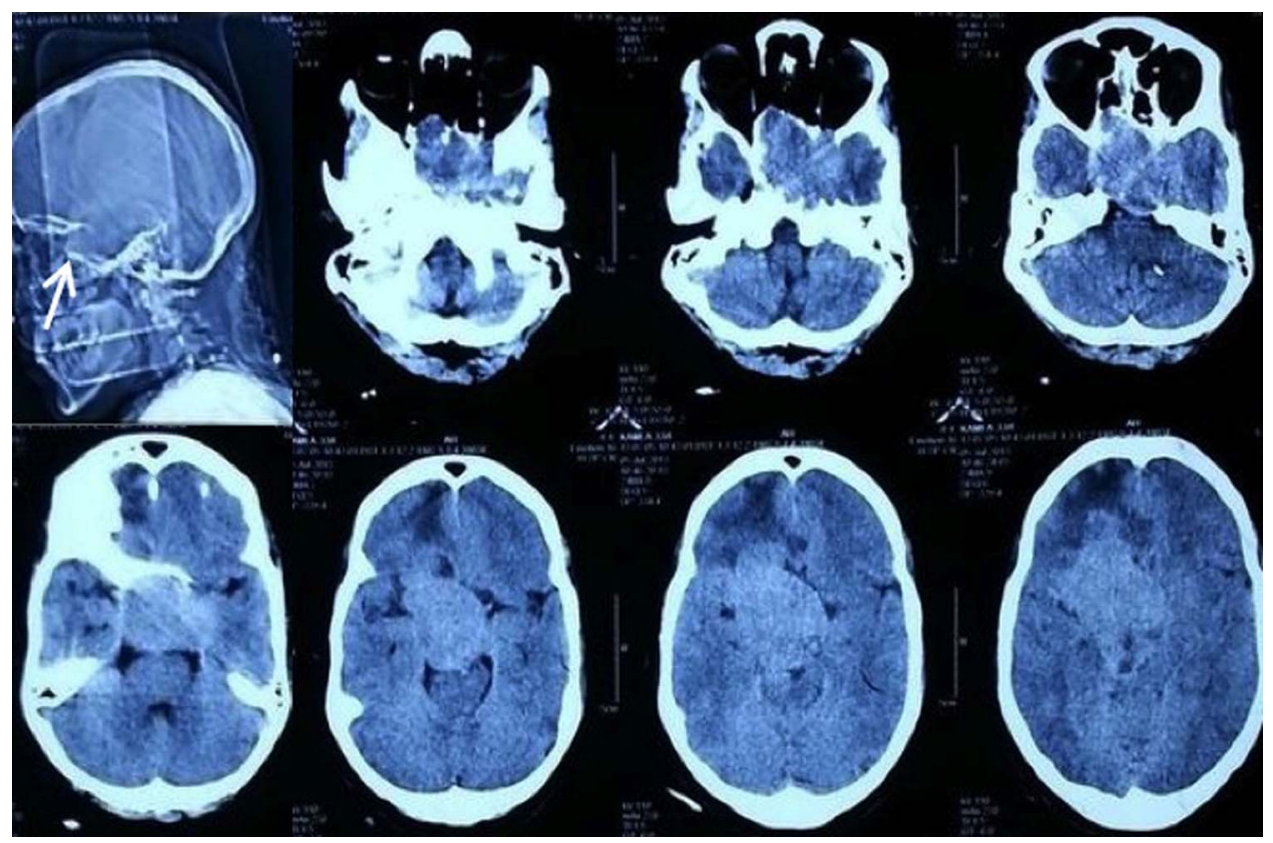

Figure 1 Non-contrast CT axial sections showing enlarged and destroyed sella (white arrow), with isodense sellar-suprasellar lesion with significant parasellar extension. 
Figure 2 MRI T2-weighted image axial sections showing hyperintense parasellar extension, with tumour compressing over the right cerebral peduncle. sellar lesion with suprasellar and

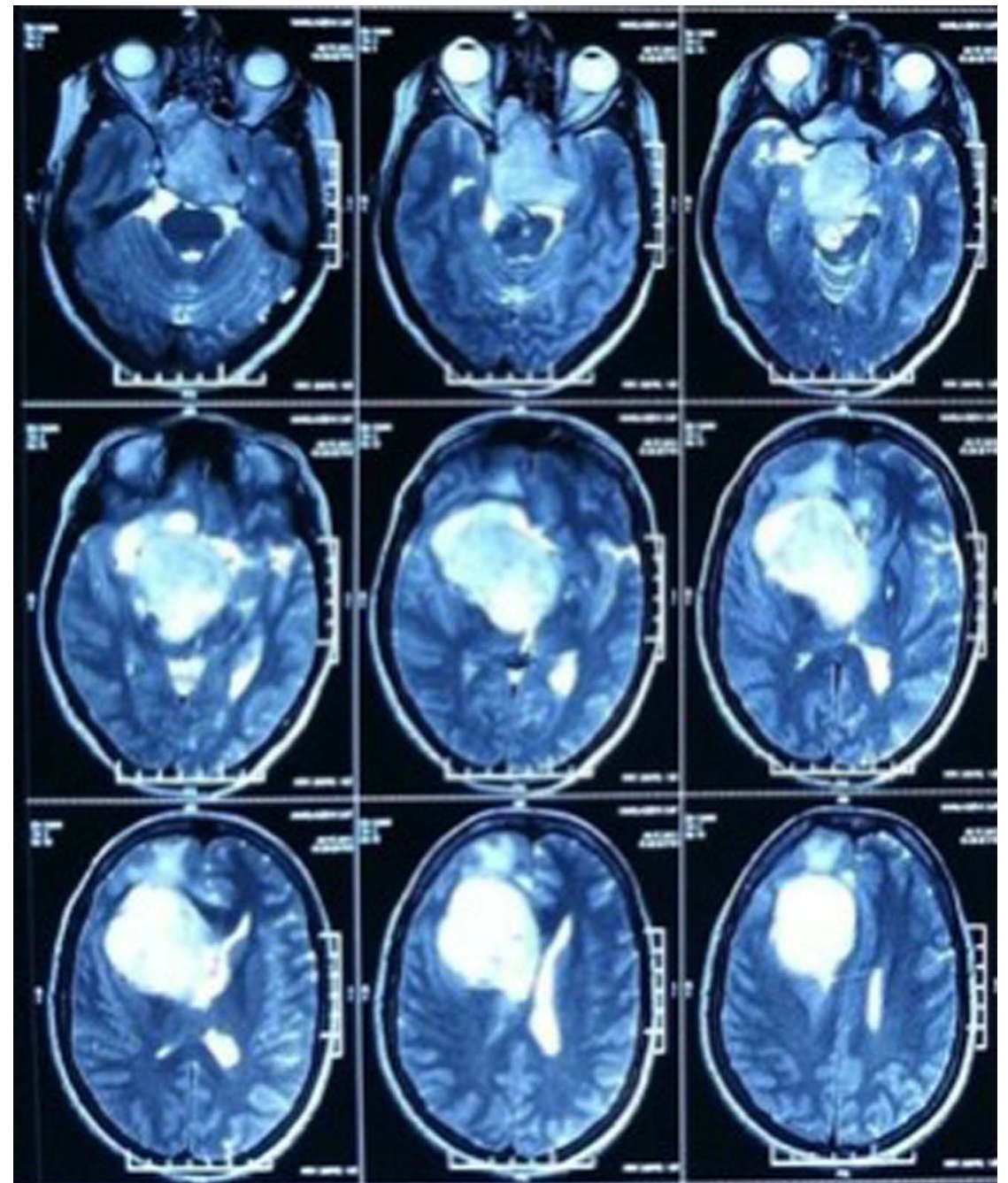

Figure 3 MRI T2-weighted image coronal sections showing hyperintense sellar lesion with suprasellar and parasellar extension, with cystic component in the anterosuperior part of tumour.

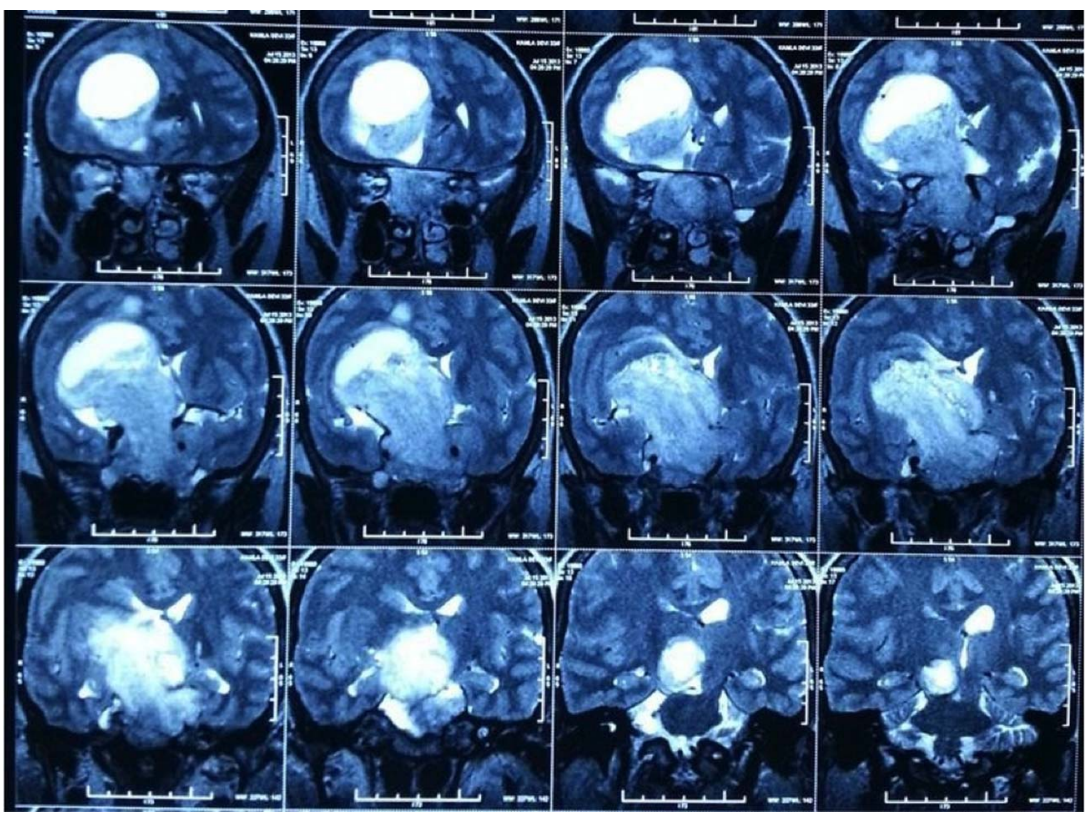




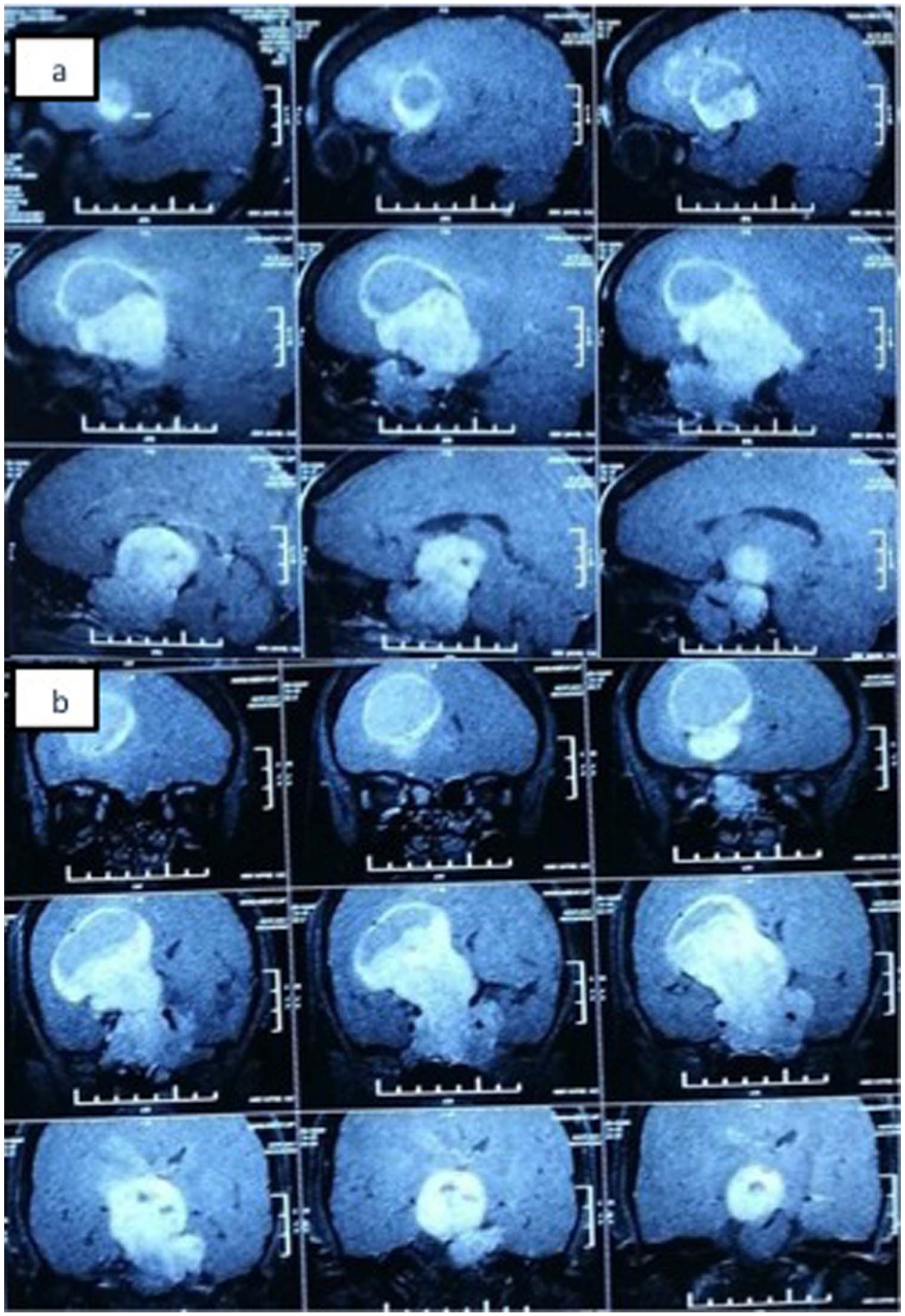

Figure 4 (A and B) MRI contrast-enhanced sagittal and coronal images showing sellar lesion with suprasellar and parasellar extension with intense contrast enhancement.

\section{Learning points}

- Pituitary adenomas can sometimes achieve huge sizes.

- Complete tumour excision is difficult to achieve in such large tumours.

- High mortality rates are reported in the literature following excision of giant pituitary adenomas.

Contributors All the authors contributed equally in formatting and editing the manuscript.
Competing interests None.

Patient consent Obtained.

Provenance and peer review Not commissioned; externally peer reviewed.

\section{REFERENCES}

1 Sinha S, Sharma BS. Giant pituitary adenomas — an enigma revisited. Microsurgical treatment strategies and outcome in a series of 250 patients. Br J Neurosurg 2010;24:31-9.

2 Symon L, Jakubowski J, Kendall B. Surgical treatment of giant pituitary adenomas. J Neurol Neurosurg Psych 1979;42:973-82.

3 Mortini P, Barzaghi R, Losa $M$, et al. Surgical treatment of giant pituitary adenomas: strategies and results in a series of 95 consecutive patients. Neurosurgery 2007:60:993-1004. 
Copyright 2013 BMJ Publishing Group. All rights reserved. For permission to reuse any of this content visit http://group.bmj.com/group/rights-licensing/permissions.

BMJ Case Report Fellows may re-use this article for personal use and teaching without any further permission.

Become a Fellow of BMJ Case Reports today and you can:

- Submit as many cases as you like

- Enjoy fast sympathetic peer review and rapid publication of accepted articles

- Access all the published articles

- Re-use any of the published material for personal use and teaching without further permission

For information on Institutional Fellowships contact consortiasales@bmjgroup.com

Visit casereports.bmj.com for more articles like this and to become a Fellow 